\title{
Spatial assessment of water quality affected by the land-use changes along Kuantan river basin
}

\begin{abstract}
This study addresses the effects of development on water quality in the Kuantan River Basin from 2003 to 2008. Chemometrics analysis namely MLR, HACA, DA and PCA was utilised as part of the methods for this study. From the result, MLR was irrefutably proven as an efficient predicting method for missing data. HACA classified seven stations as Low Polluted Stations (LPS), six stations as Moderate Polluted Stations (MPS) and two stations as High Polluted Stations (HPS). DA result depicted the accuracy rate for all reclassified data was $83.61 \%$ respectively, while the constituting parameters namely Dissolved Oxygen (DO), Escherichia coli (E. coli), pH, Phosphate (PO4), Chemical Oxygen Demand (COD), and Chloride $(\mathrm{Cl})$, gave the biggest impacts towards water quality by means of forward and backward stepwise methods. The PCA result after varimax rotation indicated that five varimax factors have presented strong parameter coefficient exceeding 0.7 by E. coli, coliform, Dissolved Solids (DS), Total Solids (TS), Chlorine (Cl), Ammonical Nitrogen (NH3NL), nitrate and $\mathrm{pH}$. The relationship between land use and water quality denoted that after applying Spearman correlation based on $90 \%$ interval population distribution, aspects influencing the rate of DO was successfully identified.
\end{abstract}

Keyword: Cluster analysis; Discriminant analysis; Principal component analysis; Multiple linear regression; Spearman correlation 